\title{
Association between time-related changes in routine blood morphological parameters and renal function after transcatheter aortic valve implantation - a preliminary study
}

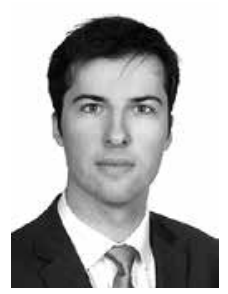

Konrad Stelmark ${ }^{1}$, Eli Adrian Zaher ${ }^{1}$, Anna Olasińska-Wiśniewska², Michael Adesina ${ }^{1}$, Alicia Dragone ${ }^{1}$, Martha Isaac ${ }^{1}$, Marcin Misterski², Marek Grygier ${ }^{3}$, Mateusz Puślecki², Maciej Lesiak ${ }^{3}$, Marek Jemielity², Bartłomiej Perek ${ }^{2}$

${ }^{1}$ Student Scientific Group, Poznan University of Medical Sciences, Poznan, Poland

2Department of Cardiac Surgery and Transplantology, Poznan University of Medical Sciences, Poznan, Poland

${ }^{3} 1^{\text {st }}$ Department of Cardiology, Poznan University of Medical Sciences, Poznan, Poland

Kardiochirurgia i Torakochirurgia Polska 2021; 18 (3): 152-158

\begin{abstract}
Introduction: Transcatheter aortic valve implantation (TAVI) although minimally invasive is still accompanied by changes in blood morphological parameters, some of them linked to unfavorable outcomes.

Aim: To find any association between changes in blood morphology reflecting an inflammatory response and acute kidney injury (AKI). Material and methods: This study involved 176 consecutive transfemoral TAVI patients with a mean age of $78.4 \pm 7.0$ years. Serum creatinine concentration (CREA) and blood morphology were analyzed in the blood samples taken before the procedure, then approximately 1, 24, 48 and 72 hours after the procedure, and lastly at the time of discharge. Post-procedural maximal or minimal values ( $\mathrm{max} / \mathrm{min}$ ) and $\mathrm{max} / \mathrm{min}$-to-bs ratio of the laboratory parameters were also calculated.

Results: Leucocyte (WBC) and neutrophil (NEUT) counts increased significantly after the procedure whereas lymphocyte (LYMPH) counts declined markedly, reaching the highest or lowest values 24 hours after the procedure. A significant increase in neutrophilto-lymphocyte ratio (NLR) was observed. Platelet count (PLT) dropped to a minimum at 72 hours after TAVI but at discharge did not return to the admission level. TAVI was associated with a marked increase in CREA with a peak at 48 hours after the procedure $(135.7 \pm 75.9 \mu \mathrm{M} / \mathrm{l})$. Patients with AKI $(n=65 ; 36.9 \%)$ presented more pronounced variations in relative changes in counts of all blood morphological parameters. A positive moderate $(r=0.412)$ correlation between maximal NLR and relative CREA changes was noted. Conclusions: TAVI is associated with significant changes in blood morphological parameters that reflect an inflammatory response. They are more pronounced among subjects with post-procedural AKI.
\end{abstract}

Key words: aortic stenosis, transcatheter aortic valve replacement, blood morphology, acute renal injury.

\section{Introduction}

Transcatheter aortic valve implantation (TAVI) is a minimally invasive procedure that is being more often applied in the treatment of symptomatic severe aortic stenosis (AS) [1]. It is used as an alternative to surgical valve replacement (SAVR) usually in elderly patients with intermediate-to-high operative risk [1, 2]. The benefits of TAVI over SAVR include reduced trauma, no application of invasive cardio-pulmonary bypass (CPB), and decline in prevalence of such complications as atrial fibrillation, respiratory failure, bleeding or acute kidney injury (AKI) [2]. The need for fluoroscopy and angiography using a contrast agent to aid in the positioning of the valve may also contribute to AKI [3]. In addition, periods of hypotension due to the rapid pacing for balloon valvuloplasty and valve deployment may also lead to this complication $[4,5]$. Together, the prevalence of AKI following TAVI is not trivial and kidney performance must be strictly monitored in the early post-procedural period [4]. Some researchers have claimed that one of the most prominent factors at the metabolic level responsible for a negative impact on kidney performance soon after TAVI and other cardiac surgical procedures is an inflammatory response and oxidative stress $[6,7]$.

\footnotetext{
Aim

Therefore, we decided to check if there was any association between blood morphological parameters reflecting inflammatory response and renal function after TAVI in a single cardiac surgical center.
} 
Material and methods

\section{Patients}

Our study involved 176 consecutive TAVI patients (96 (54.5\%) females and 80 (45.5\%) males) with the mean age of $78.4 \pm 7.0$ years who underwent TAVI through transfemoral (TF) access (TF-TAVI) between January 2013 and March 2017. Patients in whom TAVI bioprostheses were delivered through other accesses (such as transapical (TA), direct aortic (DA), or through the carotid artery (CA)) and those

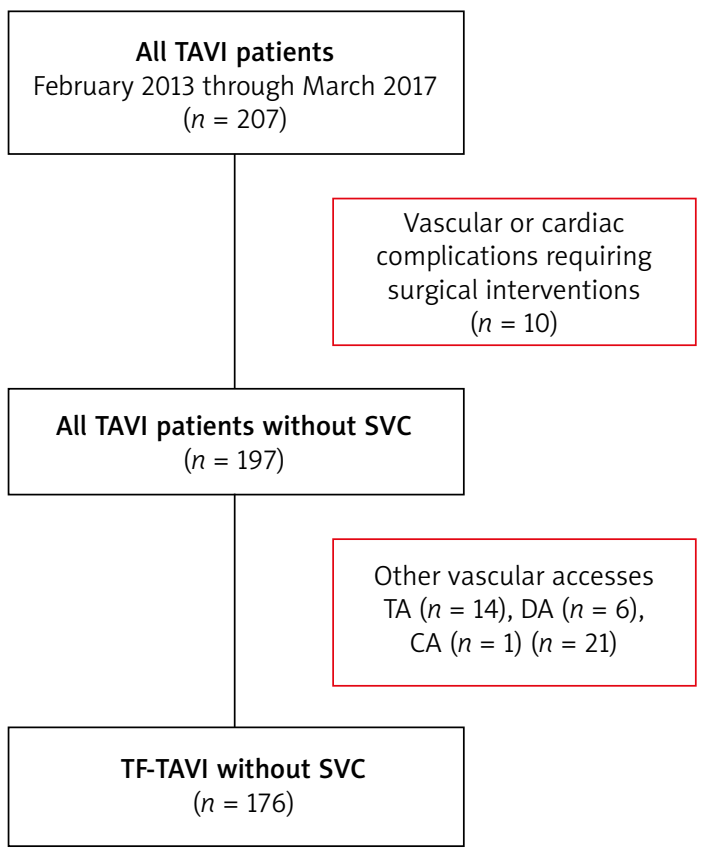

Figure 1. Enrollment process for the current study

CA - carotid artery (access), DA - direct aortic (access), SVC - serious vascular complications, TA - transapical (access), TAVI - transcatheter aortic valve implantation, TF - transfemoral (access).

Table II. Preoperative laboratory results $(n=176)$

\begin{tabular}{lc} 
Parameter & Value \\
WBC $\left[\times 10^{9} / l\right]$ & $7.24 \pm 2.05$ \\
\hline NEUT $\left[\times 10^{9} / I\right]$ & $4.99 \pm 1.83$ \\
\hline LYMPH $\left[\times 10^{9} / l\right]$ & $1.41 \pm 0.59$ \\
\hline RBC $\left[\times 10^{12} / /\right]$ & $4.27 \pm 0.51$ \\
\hline HGB $[\mu \mathrm{M} / \mathrm{l}]$ & $7.93 \pm 0.99$ \\
\hline HCT & $0.38 \pm 0.04$ \\
\hline RDW $(\%)$ & $14.9 \pm 1.4$ \\
\hline PLT $\left[\times 10^{9} / l\right]$ & $207 \pm 73$ \\
\hline MPV $[\mathrm{fl}]$ & $8.90 \pm 1.10$ \\
\hline NLR & $3.5(2.5-4.6)$ \\
\hline Creatinine $[\mu M / l]$ & $106.3 \pm 35.8$ \\
\hline eGFR $\left[\mathrm{ml} / \mathrm{min} / 1.73 \mathrm{~m}^{2}\right]$ & $57.0 \pm 16.7$ \\
\hline
\end{tabular}

\#Data are presented as the mean with standard deviation (SD) (if normally distributed) or the median with interquartile range (IOR) (the others).

eGFR - estimated glomerular filtration rate, HGB - hemoglobin concentration, HCT - hematocrit, LYMPH - lymphocyte count, MPV - mean platelet volume, NEUT - neutrophil count, NLR - neutrophil-to-lymphocyte ratio, PLT - platelet count, RBC - red blood cell count, RDW - red blood cell distribution width, WBC - white blood cell count.
Table I. Preoperative demographics and selected clinical data $(n=176)$

\begin{tabular}{|c|c|}
\hline Parameter & Value \\
\hline Age [years] & $78.4 \pm 7.0$ \\
\hline Females & $96(54.5)$ \\
\hline $\mathrm{BMI}\left[\mathrm{kg} / \mathrm{m}^{2}\right]$ & $28.0 \pm 4.7$ \\
\hline Obesity $\left(\mathrm{BMI}>30 \mathrm{~kg} / \mathrm{m}^{2}\right)$ & $55(31.3)$ \\
\hline Hypertension & $125(71.0)$ \\
\hline $\mathrm{DM}$ & $58(33.0)$ \\
\hline COPD & $37(21.0)$ \\
\hline $\operatorname{CKD}(3+)^{*}$ & $103(58.5)$ \\
\hline TIA or stroke in anamnesis & $31(17.6)$ \\
\hline MI in history & $64(36.4)$ \\
\hline Previous permanent pacemaker implantation & $27(15.3)$ \\
\hline AF & $66(37.5)$ \\
\hline EuroSCORE II (\%) & $4.8(2.9-9.2)$ \\
\hline STS risk score (\%) & $5.2(3.3-14.3)$ \\
\hline \multicolumn{2}{|c|}{$\begin{array}{l}\text { \#Continuous data are presented as the mean with standard deviation (SD) } \\
\text { (if normally distributed) or the median with interquartile range (IQR) (the other } \\
\text { while categorical variables are presented as the number (n) with percentage (\%) } \\
\text { *if eGFR (estimated glomerular filtration rate) was below } 60 \mathrm{ml} / \mathrm{min} / 1.73 \mathrm{~m}^{2} \text {. } \\
\text { AF - atrial fibrillation, AKI - acute kidney injury, BMI - body mass index, } \\
\text { CKD - chronic kidney disease, COPD - chronic obstructive pulmonary disease, } \\
\text { DM - diabetes mellitus, MI - myocardial infarction, STS - Society of Thoracic } \\
\text { Surgeons, TIA - transient ischemic attack. }\end{array}$} \\
\hline
\end{tabular}

who had serious vascular complications and/or cardiac tamponade requiring surgical interventions were excluded from the study (Figure 1). Preoperative demographics and selected clinical data are summarized in Table I.

Due to the retrospective nature of our analysis, we did not apply to the Local Bioethical Committee for approval. However, all principles outlined in the Declaration of Helsinki were respected.

\section{Preoperative examinations}

All severely symptomatic AS subjects were qualified for the TAVI procedure by the institutional multidisciplinary heart team consisting of an interventional cardiologist, cardiac surgeon, and specialist in echocardiography. This was done on the basis of available clinical data, laboratory and imaging studies' findings such as coronary angiography, transthoracic echocardiography (TTE) and contrastenhanced computed tomography (CT) with off-line reconstruction to evaluate the aortic valve and access site (femoral and iliac arteries).

In our analysis, we paid special attention to the basic morphological parameters such as counts of leucocytes (white blood cells - WBC), neutrophils (NEUT), lymphocytes (LYMPH), platelet (PLT), mean platelet volume (MPV), and markers of renal function (creatinine (CREA) and estimated glomerular filtration rate (eGFR) according to the MDRD formula). Moreover, a blood morphology-derived marker of inflammation, neutrophil-to-lymphocyte (NLR) ratio, was also assessed (Table II). 


\section{Aortic valve implantation}

General anesthesia or deep sedation was used during the procedure. A temporary pacemaker was inserted from the femoral vein for rapid pacing and as a backup in case of iatrogenic complete atrioventricular block.

In patients with the percutaneous femoral approach, two Proglides were introduced before insertion of the vascular sheath. The following aortic bioprostheses were implanted: CoreValve or CoreValve Evolut R (Medtronic Inc., $n=139$ ), Lotus (Boston Scientific; $n=35$ ), and Accurate (Symetis SA, $n=2$ ). Once the prosthesis was correctly positioned and deployed, contrast injection was performed to assess the presence and degree of paravalvular leak (PVL). Control angiography of the access site was performed to assess vessel patency and possible bleeding. At the end of the procedure, TTE was obligatory to assess valve function and control the pericardial sac.

\section{Postoperative course}

All patients after the TAVI procedure were meticulously monitored. Renal function was monitored systematically by means of serum CREA concentration. Incidents of acute kidney injury were evaluated adopting the criteria of the VARC-3 Writing Committee [8]. Additionally, blood morphology was assessed every 12 hours throughout the first 2 days, then on a daily basis. For purposes of this study, we collected such data before (baseline, bs) then 1, 24, 48, and 72 hours following TAVI interventions and eventually at the time of discharge. Post-procedural maximal or minimal values ( $\mathrm{max} / \mathrm{min}$ ) and $\mathrm{max} / \mathrm{min}$-to-bs ratio of these parameters were also calculated.

No time-related changes in erythrocyte parameters were assessed since in some patients, red blood cell concentrates had to be transfused; therefore the results could not be considered as having any scientific value.

\section{Statistical analysis}

First, all continuous variables were checked for normality by means of the Shapiro-Wilk $W$ test. Those meeting the criteria of a normal distribution were presented as the mean with standard deviation (SD) and then analyzed using repeated-measures ANOVA followed by the post hoc Tukey HSD test (for time-related changes within groups). Otherwise (i.e., for non-normally distributed continuous variables), they were presented as the median with interquartile range (IQR: $1^{\text {st }}$ to $3^{\text {rd }}$ quartile) and then analyzed statistically by the non-parametric ANOVA Friedmann test followed by Dunn's multiple comparisons of ranks. Correlations between blood morphology-derived inflammatory markers were tested using Spearman's rank correlation coefficient. Categorical variables were presented as the numbers $(n)$ with percentage (\%) and then compared by means of the $\chi^{2}$ test. The latter was interpreted using the scale provided by Chung and Salkin, where an $r$ between 0.8 and 1.0 (or -0.8 and -1.0 ) was defined as very strong, between 0.6 and 0.8 as strong, between 0.4 and 0.6 as moderate, between 0.2 and 0.4 as a weak relationship [9]. A p-value $<0.05$ was considered statistically significant. All statistical analyses were performed using Statistica 13.3 software (TIBCO Software Inc., Palo Alto, CA, USA).

\section{Results \\ Time-related changes of basic morphological parameters}

Both WBC and NEUT counts increased significantly $(p<0.001)$ after the procedure and reached peak values 24 hours afterward, from $7.24 \pm 2.05$ to $9.51 \pm 3.16 \times 10^{9} / /$ and from $4.99 \pm 1.83$ to $7.59 \pm 3.26 \times 10^{9} /$, respectively for WBC and NEUT (Figure $2 \mathrm{~A}$ ). Their levels returned to the bs values at the time of discharge. Leucocytosis $\geq 12 \times 10^{9} / /$ within the first 48 hours after TAVI was noted in 54 (30.7\%) subjects. Otherwise, LYMPH counts declined markedly ( $p<0.001)$ after the procedure with a minimum at the $24^{\text {th }}$ hour (from $1.42 \pm 0.59$ to $0.910 .49 \times 10^{9} /$ ) ) and then started to increase to reach the baseline at discharge (e.g. usually on the $7^{\text {th }}$ post-procedural day). Post-hoc analysis revealed significant differences (for all WBC, NEUT, and LYMPH) between sampling points 1 hour to 72 hours vs. baseline. Moreover, calculations of correlation revealed a very strong positive association between WBC and NEUT ( $r=0.959$; $p<0.001$ ) (Figure 3). As a consequence of the aforementioned changes, a significant increase $(p<0.001)$ in NLR was also observed and its peak value was (median: 8.16, IQR: 5.69-12.61) noted 24 hours after TAVI (Figure 2 B).

Platelet count (PLT) declined markedly with a minimum at the $72^{\text {nd }}$ hour after TAVI (from $207 \pm 74$ to $129 \pm 55 \times 10^{9} /$; $p<0.001)$. But contrary to the other blood morphology parameters at discharge, it did not return completely to the admission level (187 $\pm 85 \times 10^{9} / \mathrm{l} ; p=0.019$ vs. baseline) (Figure $2 \mathrm{C}$ ). Mean platelet volume (MPV) increased significantly during hospitalization $(p<0.001)$. A post-hoc analysis revealed that at the $48^{\text {th }}(9.4 \pm 1.2 \mathrm{fl})$ and $72^{\text {nd }}(9.5 \pm 1.2 \mathrm{fl})$ hour following the procedure, platelets were markedly larger than not only before the procedure $(8.9 \pm 1.1 \mathrm{fl} ; p<0.001$ vs. $48^{\text {th }}$ and $\left.72^{\text {nd }}\right)$ but also 1 hour $\left(9.0 \pm 1.1 \mathrm{fl} ; p=0.017 \mathrm{vs.} 48^{\text {th }}\right.$ and $p=0.006$ vs. $72^{\text {nd }}$ hour) after it. Of note, it returned to the admission value at the time of discharge $(9.1 \pm 1.2 \mathrm{fl})$ (Figure $2 \mathrm{C}$ ).

\section{Post-procedural renal function and AKI prevalence}

TAVI was associated with a significant increase $(p=0.026$ in ANOVA) in CREA concentration with a peak at 48 hours after the procedure $(135.7 \pm 75.9 \mu \mathrm{M} / \mathrm{l} ; p=0.034 \mathrm{vs}$. bs and $p=0.014$ vs. 1 hour) (Figure 2 D). Of interest, its level immediately after TAVI $(104.3 \pm 34 \mu \mathrm{M} / \mathrm{l})$ was comparable to the bs value (Table I).

Post-procedural AKI according to the VARC-3 criteria was noted in 65 (36.9\%) TAVI patients. Among blood morphological parameters they (the AKI subgroup) had both higher maximal counts and relative changes in counts of WBC, NEUT and NLR, but markedly lower LYMPH compared 


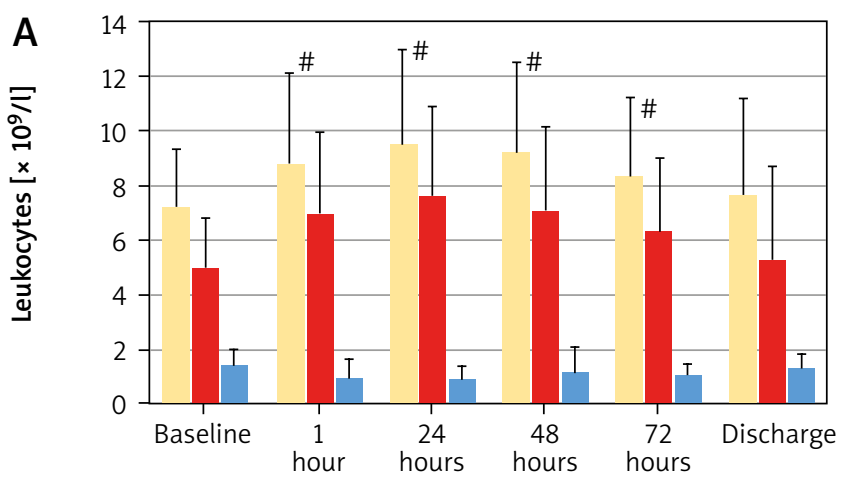

WBC NEUT $\square$ LYMPH

${ }^{\#} p<0.001$ vs. baseline (all cell types).

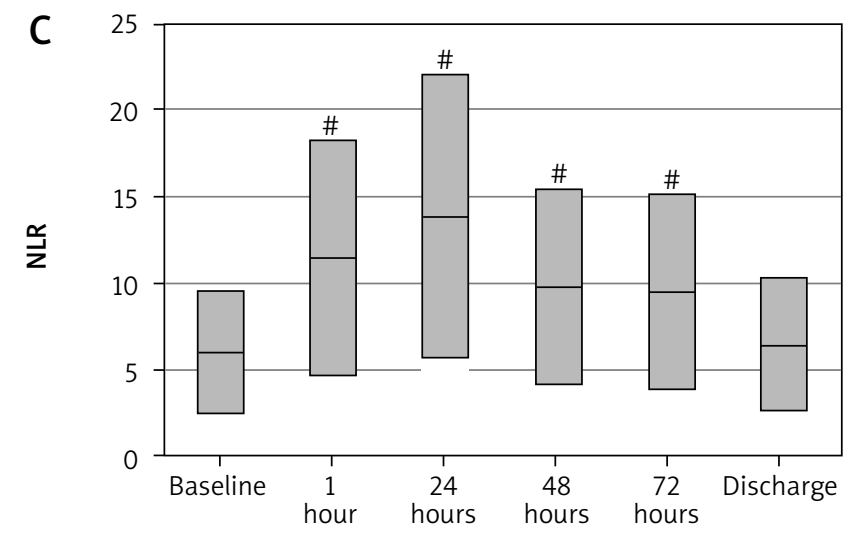

${ }^{\#} p<0.001$ vs. baseline.
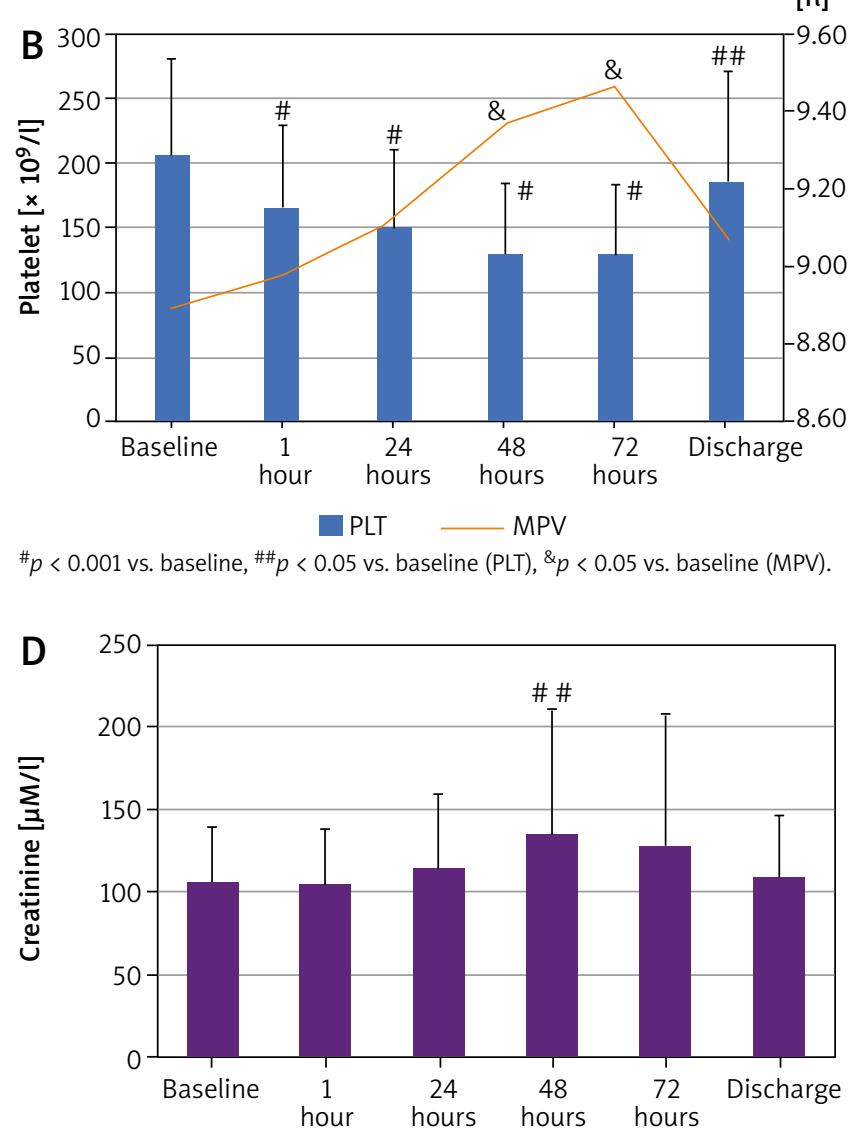

${ }^{\# \#} p<0.05$ vs. baseline.

Figure 2. Time-related changes of laboratory parameters following TAVI. Marked time-related variations were observed for leukocytes and their fractions (A) as well as for platelets (B). Consequently, a morphological parameter-derived marker of inflammation (C) changed also significantly. In the meantime, creatinine concentration increased markedly (D)

LYMPH - lymphocyte count, MPV - mean platelet volume, NEUT - neutrophil count, NLR - neutrophil-to-lymphocyte ratio, PLT - platelet count, WBC - white blood cell (leucocyte) count.

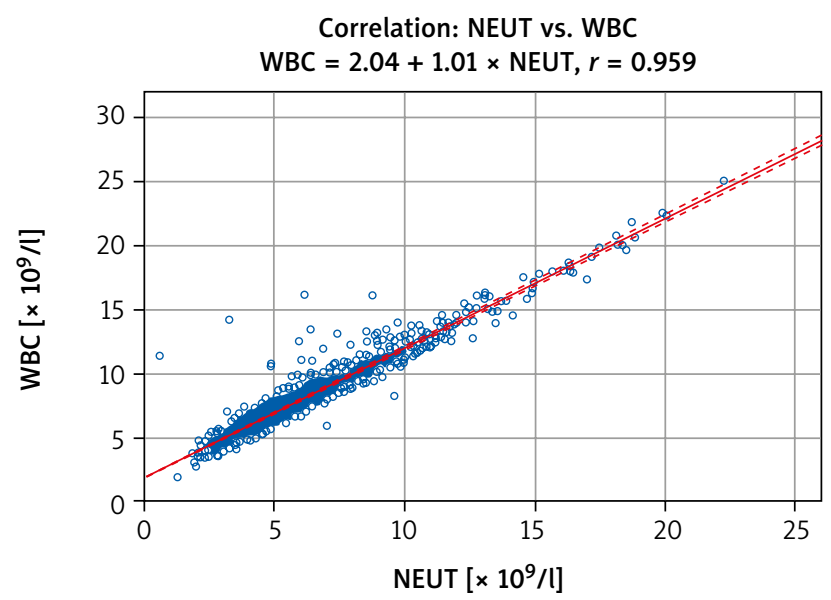

Figure 3. Correlation between WBC and NEUT counts

to individuals without AKI (non-AKI subgroup) (Table III). Although minimal counts of PLT and maximal values of MPV throughout the post-procedural period did not differ between these groups, their relative changes (e.g. max/ min-to-bs) were more pronounced in the AKI subset.

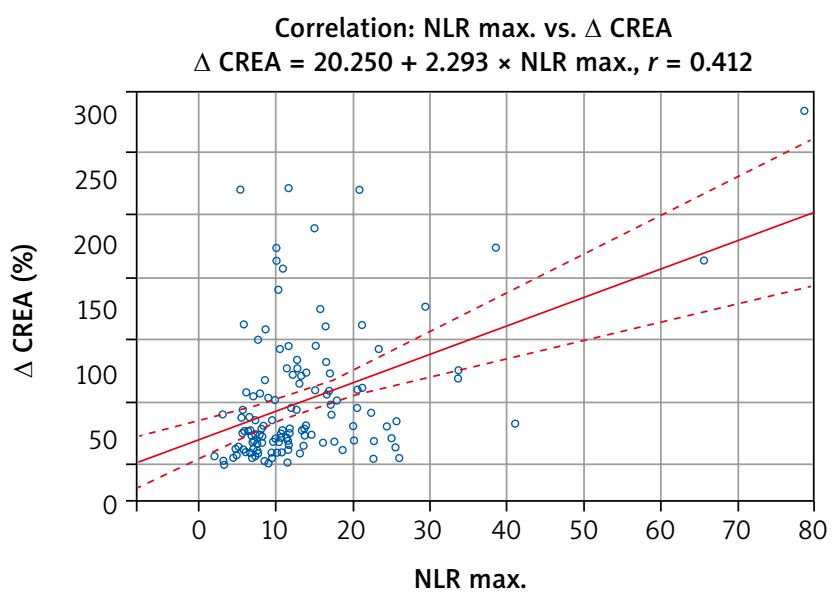

Figure 4. Correlation between NLR and relative increase in postprocedural creatinine concentration

\section{Association between blood morphology and renal function}

Correlation analysis revealed some associations between changes in values of morphological parameters and CREA concentration. Additionally, due to the fact that base- 
Association between time-related changes in routine blood morphological parameters and renal function after transcatheter aortic valve implantation - a preliminary study

Table III. Maximal/minimal values of morphological parameters and their relative change vs. baseline

\begin{tabular}{|c|c|c|c|c|}
\hline Parameter & $\begin{array}{c}\text { All } \\
(n=176)\end{array}$ & $\begin{array}{l}\text { Non-AKI } \\
(n=111)\end{array}$ & $\begin{array}{c}\text { AKI } \\
(n=65)\end{array}$ & $P$-value \\
\hline WBC $\max .\left[\times 10^{9} / I\right]$ & $10.99 \pm 4.03$ & $9.97 \pm 3.16$ & $12.74 \pm 4.71$ & $<0.001$ \\
\hline WBC $\max (48 \mathrm{~h}) \geq 12 \times 10^{9} / \mathrm{l}(\%)$ & $54(30.7)$ & $25(22.5)$ & $29(44.6)$ & 0.002 \\
\hline$\triangle \& W B C(\%)$ & $42.3(22.0-76.2)$ & $34.3(15.3-62.3)$ & $60.0(40.1-109.8)$ & $<0.001$ \\
\hline NEUT max. $\left[\times 10^{9} / I\right]$ & $8.94 \pm 3.80$ & $7.88 \pm 2.83$ & $10.74 \pm 4.52$ & $<0.001$ \\
\hline$\triangle$ NEUT (\%) & $68.2(37.7-125.7)$ & $60.5(24.0-96.4)$ & $94.4(53.4-143.1)$ & $<0.001$ \\
\hline LYMPH min. $\left[\times 10^{9} / \mathrm{I}\right]$ & $0.77 \pm 0.38$ & $0.82 \pm 0.38$ & $0.68 \pm 0.35$ & 0.012 \\
\hline$\Delta \mathrm{LYMPH}(\%)$ & $45.3(32.3-56.6)$ & $44.4(30.2-55.0)$ & $47.4(38.0-58.7)$ & 0.055 \\
\hline NLR max. & $10.4(7.3-14.9)$ & $8.4(6.7-11.7)$ & $13.2(10.1-20.9)$ & $<0.001$ \\
\hline$\Delta \mathrm{NLR}(\%)$ & $178.2(114.7-311.3)$ & $158.8(92.0-248.1)$ & $228.8(145.9-359.7)$ & 0.004 \\
\hline PLT min. $\left[\times 10^{9} / I\right]$ & $120 \pm 49$ & $120 \pm 44$ & $119 \pm 57$ & 0.862 \\
\hline$\Delta \mathrm{PLT}(\%)$ & $40.2(30.8-48.9)$ & $39.7(30.4-46.7)$ & $42.9(32.9-52.4)$ & 0.036 \\
\hline MPV max. [fl] & $9.8 \pm 1.3$ & $9.7 \pm 1.7$ & $10.1 \pm 1.5$ & 0.061 \\
\hline$\triangle M P V(\%)$ & $8.4(3.4-15.7)$ & $6.7(2.4-13.5)$ & $13.3(5.0-19.2)$ & 0.002 \\
\hline
\end{tabular}

\#Data are presented either as the mean with standard deviation (SD) (if normally distributed) or the median with interquartile range (IQR) (the others) whereas categorical data are presented as the number $(n)$ with percentage (\%); ${ }^{*}$ it refers to the comparison between AKI and non-AKI subgroups (bolded values indicate those of statistical significance); \&a relative increase or decrease of morphological parameters between their maximal (max. in Table III) or minimal (min. in Table III) vs. baseline values. AKI - acute kidney injury, LYMPH - lymphocyte count, MPV - mean platelet volume, NEUT - neutrophil count, NLR - neutrophil-to-lymphocyte ratio, PLT - platelet count, WBC - white blood cell count.

Table IV. Associations between absolute values and relative chang es in blood morphological parameters and creatinine concentration

\begin{tabular}{|c|c|c|}
\hline Parameter & Max. creatinine $[\mu \mathrm{M} / \mathrm{I}]$ & $\Delta$ creatinine $(\%)$ \\
\hline WBC $\max .\left[\times 10^{9} / \mathrm{I}\right]$ & $0.305^{*}$ & 0.306 \\
\hline$\triangle \& W B C(\%)$ & 0.297 & 0.322 \\
\hline NEUT $\max .\left[\times 10^{9} / I\right]$ & 0.334 & 0.350 \\
\hline$\Delta$ NEUT $(\%)$ & 0.230 & 0.303 \\
\hline LYMPH min. $\left[\times 10^{9} / \mathrm{I}\right]$ & -0.171 & -0.210 \\
\hline$\triangle \mathrm{LYMPH}(\%)$ & 0.124 & 0.086 \\
\hline NLR max. & 0.361 & 0.412 \\
\hline$\Delta \mathrm{NLR}(\%)$ & 0.197 & 0.281 \\
\hline PLT min. $\left[\times 10^{9} / 1\right]$ & -0.065 & -0.037 \\
\hline$\Delta \mathrm{PLT}(\%)$ & 0.118 & 0.168 \\
\hline MPV max. $[\mathrm{fl}]$ & 0.120 & 0.041 \\
\hline$\triangle M P V(\%)$ & 0.185 & 0.251 \\
\hline
\end{tabular}

\#' $r$ ' values are presented; \&a relative increase or decrease of morphological parameters between their maximal (max. in Table IV) or minimal (min. in Table IV) vs. baseline values; ${ }^{*}$ bolded values indicate those of statistical significance. LYMPH - lymphocyte count, MPV - mean platelet volume, NEUT - neutrophil count, NLR - neutrophil-to-lymphocyte ratio, PLT - platelet count, WBC - white blood cell count.

line parameters feature some variability, the correlation between their relative changes was also calculated. The strongest, although still moderate (see definition above), correlation between NLR and relative variation in CREA levels (Figure 4) was noted. The other, rather weak correlations, are outlined in Table IV.

\section{Discussion}

Our study showed that TAVI, while being considered a minimally invasive procedure, is still associated with an inflammatory response reflected by marked changes in some blood morphological parameters. Previously, leucocytosis $\geq 12.0 \times 10^{9} / \mathrm{l}$, among other parameters, was shown to characterize the systemic inflammatory response (SIRS) that can negatively impact outcomes after TAVI, including mortality [10]. Based on this hematological parameter, the incidence of SIRS after TAVI in our group (approximately $30 \%$ ) was comparable or even slightly lower than in the previous reports $[6,10,11]$. It means that SIRS after minimally invasive valve implantation may still be a problem of clinical significance $[10,11]$. Moreover, we did prove that the WBC count increase resulted mainly from the release of neutrophils from natural sources. In the meantime, LYMPH counts declined markedly after the procedure. Routine blood analysis does not allow to distinguish subpopulations of LYMPH, although the majority of them are probably T subtypes of LYMPH. It was proved earlier that the inflammatory level greatly influenced the differentiation and activity of $\mathrm{T}$ lymphocyte populations and that exposure to high levels of reactive oxygen species (ROS) decreases the capacity of their activation and proliferation [12].

As a consequence, the NLR value also changed markedly following the TAVI procedure. Recently, NLR has been an emerging biomarker of inflammation and of significant prognostic value. Therefore it has been studied in many disciplines of medicine, including cardiovascular medicine and surgery, in the last few years [13-15]. Among many others, a raised NLR value was also found to be associated with increased cardiac mortality, amputation in vascular operations, and raised risk of post-operative re-intubation [13]. In our experience, the NLR value was higher among individuals who developed AKI in the early postoperative period.

Of interest, the shape of changes in PLT and MPV in our TF-TAVI group looks like a mirror reflection. A decline in PLT 
is usually accompanied by an increase in MPV. The fluctuations in these basic thrombocyte parameters were found previously after cardiovascular interventions and were influenced by procedural invasiveness [16, 17]. Fewer changes in comparison to the baseline values were noted after minimally invasive procedures on the stenotic aortic valves [17]. The decrease in PLT was reported within a wide range from less than $30 \%$ to more than $50 \%$; therefore our group was similar to the previous studies $[16,18,19]$. Many factors have been shown previously to contribute to a marked decrease in PLT, including advanced age, lower body mass, inevitable intraprocedural whole blood loss, the amount of the contrast infused, the time of the procedure, application of balloon-expandable prostheses, and the residual transvalvular gradient [18-20]. Of note, this effect is usually temporary, and not uncommonly 24 hours later (e.g. on the third post-procedural day) at least partial recovery is seen [21]. More pronounced drops in PLT were shown to be associated with poorer clinical outcomes, in our group in higher prevalence of AKI [16]. Declining PLT also reveals platelet activation and aggregation in a postoperative prothrombotic state. It can be a partial explanation why the nadir (the minimal value) in the early postprocedural period was lower among subjects who developed AKI, which may be due to endothelial dysfunction and platelet hyperactivity in organ microcirculation. MPV is another platelet parameter that was found to have predictive value for the development of early adverse events following cardiac procedures. It was found to be a predictor of mortality and morbidity (particularly atrial fibrillation) after coronary artery bypass grafting (CABG) [22]. Higher MPV after invasive surgical procedures may reflect two vascular trauma-initiated biological processes. In the first one, cytokines released to the vascular system together with ROS provoke the bone marrow to produce new and larger platelets [23]. On the other hand, circulating platelets respond to vessel injury by changes in morphological shape (and tend to be larger) and likely aggregation to prevent blood loss [24].

Herein, more pronounced changes in the above-discussed blood morphological parameters were noted in the patients who developed transient renal dysfunction fulfilling criteria of AKI according to the VARC-3 [8]. Therefore, our study supported earlier opinions that one of the mechanisms responsible for AKI could be inflammatory reactions [25]. We observed in this study a significant correlation between the peak value of NLR (an inflammatory marker) and relative change in creatinine level after the procedure. Additionally, higher NLR as well as an increased rate of leukocytosis as a valuable marker of SIRS, with possibly severe consequences, among AKI cases were proved herein.

The authors of this study are aware of obvious limitations related to retrospective data analysis. However, we hope this preliminary report warrants further clinical research to find more mechanisms involved in the development of AKI following TAVI procedures. We plan to assess the impact of some blood morphological variables on the early and long-term prognosis. Eventually, a better under- standing of pathomechanisms leading to AKI can help develop more effective preventive strategies and make TAVI procedures safer for high-risk patients.

\section{Conclusions}

Transcatheter implantation of the aortic valve, although minimally invasive, is associated with significant changes in blood morphological parameters that reflect an inflammatory response to procedural trauma. They are more pronounced among subjects with post-procedural acute kidney injury.

\section{Disclosure}

The authors report no conflict of interest.

\section{References}

1. Rahhab Z, El Faquir N, Tchetche D, Delgado V, Kodali S, Mara Vollema E, Bax J, Leon MB, Van Mieghem NM. Expanding the indications for transcatheter aortic valve implantation. Nat Rev Cardiol 2020; 17: 75-84.

2. Terré JA, George I, Smith CR. Pros and cons of transcatheter aortic valve implantation (TAVI). Ann Cardiothorac Surg 2017; 6: 444-452.

3. Lichtenstein SV, Cheung A, Ye J, Thompson CR, Carere RG, Pasupati S, Webb JG. Transapical transcatheter aortic valve implantation in humans: initial clinical experience. Circulation 2006; 114: 591-596.

4. Zaleska-Kociecka M, Dabrowski M, Stepinska J. Acute kidney injury after transcatheter aortic valve replacement in the elderly: outcomes and risk management. Clin Interv Aging 2019; 14: 195-201.

5. Elhmidi Y, Bleiziffer S, Deutsch MA, Krane M, Mazzitelli D, Lange R, Piazza N. Acute kidney injury after transcatheter aortic valve implantation: incidence, predictors and impact on mortality. Arch Cardiovasc Dis 2014; 107: 133-139.

6. Rettig TC, Rigter S, Nijenhuis VJ, van Kuijk JP, ten Berg JM, Heijmen RH, van de Garde EM, Noordzij PG. The systemic inflammatory response syndrome predicts short-term outcome after transapical transcatheter aortic valve implantation. J Cardiothorac Vasc Anesth 2015; 29: 283-287.

7. Scrascia G, Rotunno C, Simone S, Montemurno E, Amorese L, De Palo M, Castellano G, Pertosa GB, Gesualdo L, Paparella D. Acute kidney injury in high-risk cardiac surgery patients: roles of inflammation and coagulation. J Cardiovasc Med 2017; 18: 359-365.

8. Généreux P, Piazza N, Alu MC, Nazif T, Hahn RT, Pibarot P, Bax JJ, Leipsic JA, Blanke P, Blackstone EH, Finn MT, Kapadia S, Linke A, Mack MJ, Makkar R, Mehran R, Popma JJ, Reardon M, Rodes-Cabau J, Van Mieghem NM, Webb JG, Cohen DJ, Leon MB. Valve Academic Research Consortium 3: updated endpoint definitions for aortic valve clinical research. Eur Heart J 2021; 42: 1825 1857.

9. Chung MK. Correlation coefficient. In: Encyclopedia of Measurement and Statistics. Salkin NJ (ed). Sage Publications, London 2007; 189-201.

10. Sinning JM, Scheer AC, Adenauer V, Ghanem A, Hammerstingl C, Schueler R, Müller C, Vasa-Nicotera M, Grube E, Nickenig G, Werner N. Systemic inflammatory response syndrome predicts increased mortality in patients after transcatheter aortic valve implantation. Eur Heart J 2012; 33: 1459-1468.

11. Schwietz T, Behjati S, Gafoor S, Seeger F, Doss M, Sievert H, Zeiher AM, Fichtlscherer S, Lehmann R. Occurrence and prognostic impact of systemic inflammatory response syndrome in transfemoral and transapical aortic valve implantation with balloon- and self-expandable valves. Eurolntervention 2015; 10: 1468-1473.

12. Moro-García MA, Mayo JC, Sainz RM, Alonso-Arias R. Influence of inflammation in the process of $\mathrm{T}$ lymphocyte differentiation: proliferative, metabolic, and oxidative changes. Front Immunol 2018; 9: 339.

13. Tan TP, Arekapudi A, Metha J, Prasad A, Venkatraghavan L. Neutrophil-lymphocyte ratio as predictor of mortality and morbidity in cardiovascular surgery: a systematic review. ANZ J Surg 2015; 85: 414-419.

14. Radulescu D, Baleanu VD, Padureanu V, Radulescu PM, Bordu S, Patrascu S, Socea B, Bacalbasa N, Surlin MV, Georgescu I, Georgescu EF. Neutrophil/lymphocyte ratio as predictor of anastomotic leak after gastric cancer surgery. Diagnostics 2020; 10: 799. 
Association between time-related changes in routine blood morphological parameters and renal function after transcatheter aortic valve implantation - a preliminary study

15. Seo WW, Park MS, Kim SE, Lee JH, Park DG, Han KR, Oh DJ, Hyon MS. Neutrophil-lymphocyte ratio as a predictor of venous thromboembolism after total knee replacement. J Knee Surg 2021; 34: 171-177.

16. Gallet R, Seemann A, Yamamoto M, Hayat D, Mouillet G, Monin JL, Gueret P, Couetil JP, Dubois-Randé JL, Teiger E, Lim P. Effect of transcatheter (via femoral artery) aortic valve implantation on the platelet count and its consequences. Am J Cardiol 2013; 111: 1619-1624.

17. Komosa A, Perek B, Rzymski P, Poniedziałek B, Grygier M, Siniawski A, Szabatowska K, Siller-Matula J, Jemielity M, Misterski M, Lesiak M. Platelet function in patients undergoing surgical and transcatheter aortic valve replacement: a comparative study. Kardiol Pol 2021; 79: 554-561.

18. Yamada Y, Miura D, Takamori A, Nogami E, Yunoki J, Sakaguchi Y. Predictors of short-term thrombocytopenia after transcatheter aortic valve implantation: a retrospective study at a single Japanese center. BMC Res Notes 2020; 13: 536.

19. Abu Khadija H, Ayyad O, Haberman D, Gandelman G, Poles L, Jonas M, Volodarsky I, Kweider MA, Maximovskih A, Shimoni S, George J, Blatt A. Contemporary transcatheter aortic valve implantation related thrombocytopenia. Catheter Cardiovasc Interv 2021; 98: E139-E144.

20. Hernández-Enríquez M, Chollet T, Bataille V, Campelo-Parada F, Boudou N, Bouisset F, Grunenwald E, Porterie J, Freixa X, Regueiro A, Sabaté M, Carrié D,
Marcheix B, Lhermusier T. Comparison of the frequency of thrombocytopenia after transfemoral transcatheter aortic valve implantation between balloonexpandable and self-expanding valves. Am J Cardiol 2019; 123: 1120-1126.

21. Mitrosz M, Kazimierczyk R, Sobkowicz B, Waszkiewicz E, Kralisz P, Frank M, Piszcz J, Galar M, Dobrzycki S, Musial WJ, Hirnle T, Kaminski KA, Tycinska AM. The causes of thrombocytopenia after transcatheter aortic valve implantation. Thromb Res 2017; 156: 39-44.

22. Wang XY, Yu HY, Zhang YY, Wang YP, Feng XH, Li ZP, Du XJ, Gao W. Serial changes of mean platelet volume in relation to Killip Class in patients with acute myocardial infarction and primary percutaneous coronary intervention. Thromb Res 2015; 135: 652-658.

23. Chen S, Su Y, Wang J. ROS-mediated platelet generation: a microenvironment-dependent manner for megakaryocyte proliferation, differentiation, and maturation. Cell Death Dis 2013; 4: e722.

24. Gasparyan A, Ayvazyan L, Mikhailidis D, Kitas GD. Mean platelet volume: a link between thrombosis and inflammation? Curr Pharm Des 2011; 17: 47-58.

25. Kim WH, Park JY, Ok SH, Shin IW, Sohn JT. Association between the neutrophil/lymphocyte ratio and acute kidney injury after cardiovascular surgery: a retrospective observational study. Medicine 2015; 94: e1867. 